\title{
Comparative study of nondescent vaginal hysterectomy and abdominal hysterectomy at tertiary care centre, Maharashtra
}

\author{
Sharayu Prashant Mujumdar', Priyanka Kunal Purohit ${ }^{2}$, Shwetambari S. Navale ${ }^{2}$, \\ Chintan M. Upadhyay ${ }^{2 *}$
}

\author{
${ }^{1}$ Shrushti Fertility Centre, Chennai, Tamil Nadu, India \\ ${ }^{2}$ Department of Obstetrics and Gynecology, Dr. N. D. Desai Faculty of Medical Sciences and Research, Nadiad, \\ Gujarat, India
}

Received: 16 July 2021

Accepted: 09 August 2021

\section{*Correspondence:}

Dr. Chintan M. Upadhyay,

E-mail: drchintan1508@gmail.com

Copyright: (c) the author(s), publisher and licensee Medip Academy. This is an open-access article distributed under the terms of the Creative Commons Attribution Non-Commercial License, which permits unrestricted non-commercial use, distribution, and reproduction in any medium, provided the original work is properly cited.

\begin{abstract}
Background: Vaginal route of hysterectomy has distinct health and economic benefits in terms of less morbidity, better postoperative quality of life outcomes, reduced hospital stay and better patient satisfaction. Objectives of current study were to evaluate the appropriate route of hysterectomy (abdominal or vaginal) in terms of intra and postoperative complication, morbidity and blood loss.

Methods: This prospective study was done among 100 cases of hysterectomy of which 50 patients underwent NDVH and 50 underwent abdominal hysterectomy. This study included all emergency and booked patients having Size of uterus less than 12 weeks size, adequate uterine mobility, adequate access, adenomyosis, dysfunctional uterine bleeding, chronic PID \& fibroid uterus.

Results: Study found statistically significantly higher number of the participants with parity $3 \& 4$ in both the study groups. Bulky uterus followed by 12 and 10 weeks uterus in statistically significantly higher number of the participants of both the study groups. Duration of surgery statistically significantly less in NDVH group compare to TAH group. Fibroid was the main indication of hysterectomy in both the groups. Hemorrhage was the main intraoperative complication in both the groups. Fever \& respiratory tract infection was the main post-operative complications in both the groups.

Conclusions: Benefits of NDVH over TAH are Cosmetic advantage as less invasive, No discomfort of abdominal incision, shorter operative time, lesser blood loss, lesser intraoperative and postoperative complications, postoperative comfort is more, lesser requirement of postoperative analgesia, early ambulation and shorter hospital stay.
\end{abstract}

Keywords: Ambulation, Complication, Non-descent vaginal hysterectomy, Total abdominal hysterectomy

\section{INTRODUCTION}

Hysterectomy is the most common operation performed by gynaecologist, next to caesarean section. The first abdominal hysterectomy was performed by Charles clay in Manchester in 1843. Vaginal hysterectomy dates to ancient times. ${ }^{1}$ Traditionally, the uterus has been removed by abdominal route which gives the opportunity to inspect the ovaries and vaginal route was reserved for pelvic organ prolapse. $^{2}$ Currently, there are three main types of hysterectomy operations in practice for benign diseases; abdominal hysterectomy $(\mathrm{AH})$, vaginal hysterectomy $(\mathrm{VH})$ and laparoscopic hysterectomy (LH). AH remains the predominant method of uterine removal. This route is used for malignancies, bulky uteri or when there are adhesions and removal of uterus is not possible through vaginal route. ${ }^{3}$ Overall mortality rates for $\mathrm{AH}$ or $\mathrm{VH}$ are $0.1-0.2 \% .{ }^{4}$ Vaginal route for non-descent uterus is 
an acceptable method of hysterectomy despite previous belief that it is the contraindication in certain conditions. ${ }^{5}$

Vaginal route of hysterectomy has distinct health and economic benefits in terms of less morbidity, better postoperative quality -of-life outcomes, reduced hospital stay and better patient satisfaction. ${ }^{6}$ Criteria such as the uterine size, mobility, accessibility and the pathology confined to the uterus (no adnexal pathology or known or suspected adhesions) are mostly the incorporating factors for vaginal hysterectomy. ${ }^{3}$ Extra uterine diseases such as adnexal pathology, severe endometriosis or adhesions may preclude vaginal hysterectomy. ${ }^{7}$ So, the present study was conducted with the objectives to evaluate the appropriate route of hysterectomy (abdominal or vaginal) in terms of intra and post-operative complication, morbidity and blood loss.

\section{METHODS}

This prospective study was done among 100 cases of hysterectomy of which 50 patients underwent NDVH and 50 underwent abdominal hysterectomy at obstetrics and gynaecology department at Government medical college and hospital, Latur, Maharashtra during June 2016 to November 2018. Data collection was done after ethical permission from institutional ethical committee and informed consent of clients. This study included all emergency and booked patients having Size of uterus less than 12 weeks size, adequate uterine mobility, adequate access, adenomyosis, dysfunctional uterine bleeding, chronic PID \& fibroid uterus. This study excluded cases with size of uterus more than 12 weeks size, restricted mobility, pelvic organ prolapsed, restricted access and with adnexal masses. The cases of two groups selected by random sampling method. Before surgery, every patient was clinically evaluated and investigated. The investigations included: Haemoglobin, Blood group and Rh typing, HIV, HbsAg, chest X-ray, ECG, USG abdomen and pelvis and Pap smear. Written informed consents were taken. The data were recorded in an Excel sheet and descriptive analysis was performed with the use of Epi info statistical software, CDC, Atlanta and data are presented in the tables and figures.

\section{RESULTS}

Mean age noted was 43 and 45 years in TAH and NVDH group respectively (Table 1 ). The difference between mean age of both the groups were statistically not significant ( $\mathrm{p}>0.05$ ). Parity 1, 2, 3, 4 and 5 noted in 0,8 , $15,25,2$ of TAH group and 1, 6, 28, 12, 3 of NVDH group participants respectively. The difference between parity of both the groups were statistically significant ( $\mathrm{p}<0.05$ ). Almost 26, 2, 10, 12 participants of group TAH and $23,6,11,10$ of NVDH group have uterus bulky 8 , 10,12 weeks respectively. The difference between size of uterus according to weeks of pregnancy of both the groups were statistically significant $(\mathrm{p}<0.05)$. Duration of surgery was $95 \mathrm{~min}$ and $60 \mathrm{~min}$ in TAH and NVDH group respectively. The difference between duration of surgery of both the groups were statistically not significant $(\mathrm{p}>0.05)$.

Table 1: Socio-clinical characteristics of participants $(n=100)$.

\begin{tabular}{|c|c|c|c|}
\hline Parameter & $\begin{array}{l}\text { TAH; } \\
\mathbf{N}=\mathbf{5 0}\end{array}$ & $\begin{array}{l}\text { NVDH; } \\
\mathbf{N}=\mathbf{5 0}\end{array}$ & $\begin{array}{l}\mathbf{P} \\
\text { value }\end{array}$ \\
\hline $\begin{array}{l}\text { Age }(\text { mean } \pm \text { SD }) \\
\text { (years) }\end{array}$ & $43 \pm 6.7$ & $45 \pm 5.1$ & $0.721 * *$ \\
\hline \multicolumn{3}{|l|}{ Parity } & \multirow{6}{*}{$0.04 *$} \\
\hline 1 & 0 & 1 & \\
\hline 2 & 8 & 6 & \\
\hline 3 & 15 & 28 & \\
\hline 4 & 25 & 12 & \\
\hline 5 & 2 & 3 & \\
\hline \multicolumn{3}{|l|}{ Size of uterus (week) } & \multirow{5}{*}{$0.0009 *$} \\
\hline Bulky & 26 & 23 & \\
\hline 8 & 2 & 6 & \\
\hline 10 & 10 & 11 & \\
\hline 12 & 12 & 10 & \\
\hline $\begin{array}{l}\text { Duration of } \\
\text { surgery (mean } \pm \text { SD) } \\
\text { (minutes) }\end{array}$ & $95 \pm 13.8$ & $60 \pm 16.4$ & $0.02 * *$ \\
\hline \multicolumn{3}{|l|}{ Ambulation } & \multirow{3}{*}{$0.001 *$} \\
\hline After 24 hours & 0 & 50 & \\
\hline After 48 hours & 50 & 0 & \\
\hline $\begin{array}{l}\text { Hospital stay } \\
(\text { mean } \pm \text { SD) (days) }\end{array}$ & $12 \pm 2.6$ & $7 \pm 1.3$ & $0.03 * *$ \\
\hline \multicolumn{3}{|c|}{ Need of analgesia (days) } & \multirow{4}{*}{$0.0001 *$} \\
\hline 3 & 0 & 33 & \\
\hline $4-8$ & 45 & 17 & \\
\hline$\geq 9$ & 5 & 0 & \\
\hline
\end{tabular}

*Chi-square test, ${ }^{* *}$ Student ' $\mathrm{t}$ ' test

Ambulation noted after 24 hours in NVDH group and after 48 hours in TAH group. The difference between requirement of ambulation in both the groups were statistically significant $(\mathrm{p}<0.05)$. The mean duration of hospital stay was 12 and 7 days in TAH and NVDH group respectively. The difference between duration of hospital stay of both the groups were statistically significant $(\mathrm{p}<0.05)$. Analgesia required up to $3,4-8$ and $\geq 9$ days in $0,45,5$ participants of TAH group and 33,17 , 0 of NVDH group respectively. The difference between need of analgesia in both the groups were statistically significant $(\mathrm{p}<0.05)$.

Indication of surgery like Fibroid, adenomyosis, chronic cervicitis, adenomyosis+fibroid, DUB and endometrium polyp with fibroid noted in $23,10,7,3,6 \& 1$ of TAH group cases and 17, 15, 10, 0, 8 and 0 of NVDH group cases respectively (Table 2 ). The difference between indications of surgery in both the groups were statistically not significant ( $\mathrm{p}>0.05)$. Intra-operative complication like hemorrhage, adhesion and bladder injury noted in 10,3 \& 1 of TAH group cases and 3, 0 \& 0 of $\mathrm{NVDH}$ group cases 
respectively (Table 3). The difference between intraoperative complications of both the groups were statistically not significant $(\mathrm{p}>0.05)$. Post-operative complication like fever, wound infection, urinary tract infection, respiratory tract infection and paralytic ileus noted in 6,5,4,3 and 3 of TAH group cases and 3, 0, 3, 6 and 0 of NVDH group cases respectively. The difference between post-operative complications of both the groups were statistically significant $(\mathrm{p}<0.05)$. Mean blood loss for TAH in this study is 325, maximum being $550 \mathrm{ml}$ and minimum $100 \mathrm{ml}$. Mean blood loss for NDVH is 185 , maximum being $270 \mathrm{ml}$ and minimum is $100 \mathrm{ml}$. Blood loss is significantly more in TAH than that of NDVH.

Table 2: Distribution of patients according to indication of surgery $(n=100)$.

\begin{tabular}{|c|c|c|c|}
\hline Indication & $\begin{array}{l}\text { TAH; } \\
\mathbf{N}=\mathbf{5 0}\end{array}$ & $\begin{array}{l}\text { NVDH; } \\
\mathbf{N}=\mathbf{5 0}\end{array}$ & $\begin{array}{l}P \\
\text { value }\end{array}$ \\
\hline Fibroid & 23 & 17 & \multirow{6}{*}{$0.243 *$} \\
\hline Adenomyosis & 10 & 15 & \\
\hline Chronic cervicitis & 7 & 10 & \\
\hline Adenomyosis+fibroid & 3 & 0 & \\
\hline DUB & 6 & 8 & \\
\hline $\begin{array}{l}\text { Endometrium polyp } \\
\text { with fibroid }\end{array}$ & 1 & 0 & \\
\hline
\end{tabular}

*Chi-square test

Table 3: Intra-operative and post-operative complication $(n=100)$.

\begin{tabular}{|c|c|c|c|}
\hline Complication & $\begin{array}{l}\text { TAH; } \\
\mathbf{N}=\mathbf{5 0}\end{array}$ & $\begin{array}{l}\text { NVDH } \\
; \mathbf{N}=\mathbf{5 0}\end{array}$ & $P$ value \\
\hline \multicolumn{3}{|l|}{ Intra-operative } & \multirow{4}{*}{$0.571 *$} \\
\hline Haemorrhage & 10 & 3 & \\
\hline Adhesion & 3 & 0 & \\
\hline Bladder injury & 1 & 0 & \\
\hline \multicolumn{3}{|l|}{ Post-operative } & \multirow{6}{*}{$0.08 *$} \\
\hline Fever & 6 & 3 & \\
\hline Wound infection & 5 & 0 & \\
\hline $\begin{array}{l}\text { Urinary tract } \\
\text { infection }\end{array}$ & 4 & 3 & \\
\hline $\begin{array}{l}\text { Respiratory tract } \\
\text { infection }\end{array}$ & 3 & 6 & \\
\hline Paralytic ileus & 3 & 0 & \\
\hline
\end{tabular}

*Chi-square test

\section{DISCUSSION}

It is well known fact that $70-80 \%$ of hysterectomies done for benign condition are through abdominal route. Vaginal hysterectomies are usually performed for prolapsed case $^{8}$. With adequate vaginal access and technical skill, good uterine mobility vaginal hysterectomy can easily be achieved. The main supports of the uterus, the uterosacral and cardinal ligaments situated in close proximity to vaginal vault can be easily divided to produce descent. ${ }^{9}$ Present study found that mean age of participants of both the groups was almost similar but statistically not significant. Present study found statistically significantly higher number of the participants with parity 3 and 4 in both the study groups. This observation is comparable with the study done by Abrol et al. ${ }^{10}$

Present study observed bulky uterus followed by 12 and 10 weeks uterus in statistically significantly higher number of the participants of both the study groups. This observation is comparable with the study done by Abrol et al, Bhadra et al, Saha et al, Joshi et al and Garg et al observed in their study that most of the patients who underwent vaginal and abdominal hysterectomy are multiparous. ${ }^{8-13}$ Present study found that mean duration of surgery statistically significantly less in NVDH group compare to TAH group. Study done by Murali et al observed mean duration of surgery in NDVH group without debulking was 40 min which was compared with the study done by Gayathri et al which showed the duration of 36.7 min. ${ }^{14,15}$

Present study noted that statistically significantly lower ambulation time was required in NVDH group as compare to $\mathrm{TAH}$ group. These findings are comparable with the study done by Abrol et al and Joshi et al. ${ }^{10,12}$ Present study found that mean duration of hospital stays was statistically significantly less in NVDH group as compare to TAH group. Deshpande et al noted TAH patients stayed for 7.14 days on an average in the hospital and NDVH patients stayed for just 3.18 days on an average. ${ }^{16}$ This indeed was highly significant statistically. Similar finding observed in a study conducted by Chen et al with hospital stay length in the vaginal hysterectomy (mean hospital stay 4.5 days) group being significantly shorter than in the abdominal hysterectomy (mean hospital stay 6.3 days) group. ${ }^{17}$

Present study noted that analgesia was required for statistically significantly less days for NVDH group as compare to TAH group. These findings are comparable with the study done by Deshpande et al, Abrol et al and Murali et al. ${ }^{10,14,16}$ Present study observed that fibroid was the main indication of hysterectomy in both the groups followed by adenomyosis and chronic cervicitis. But it was statistically not significant. Studies done by Joshi et al, Abrol et al and Bhandra et al noted commonest indication in vaginal hysterectomy is DUB and commonest indication in abdominal hysterectomy is fibroid uterus. ${ }^{8,10,11}$ Similar observation also noted in study done by Singh et al, Murali et al, Deshpande et al and Bharatnur et al. ${ }^{14,16,18,19}$

Present study noted that hemorrhage was the main intraoperative complication in both the groups. Other intraoperative complications like adhesion and bladder injury were observed in only TAH group but it was statistically not significant. Present study noted that fever \& respiratory tract infection was the main post-operative complications in both the groups. Other post-operative 
complications like wound infection and urinary tract infection observed in only TAH group but it was statistically not significant. So the incidence of intra and post-operative complications were noted in higher number in participants of TAH group as compare to NVDH group. These findings correlate with the study done by Abrol et al, Deshpande et al and Joshi et al. ${ }^{10,12,16}$

\section{CONCLUSION}

NDVH is associated with lesser intraoperative blood loss and complications and comparatively less post operative morbidies as compared to TAH. Post operative complications are less as compared to TAH. NDVH allows better patient comfort and helps patients to ambulate faster as compared to TAH. Hospital stay is lesser in NDVH. Post operative comfort and recovery is faster in NDVH. Hence wherever possible in all the indicated cases, vaginal route of hysterectomy is safer, effective and better than abdominal route. Benefits of NDVH over TAH; Cosmetic advantage as less invasive, no discomfort of abdominal incision, shorter operative time, lesser blood loss, lesser intraoperative and postoperative complications, postoperative comfort is more, lesser requirement of postoperative analgesia, early ambulation and shorter hospital stay.

Funding: No funding sources

Conflict of interest: None declared

Ethical approval: The study was approved by the Institutional Ethics Committee

\section{REFERENCES}

1. Singh KC, Barman SD, Sengupta R. Choice of hysterectomy for benign disease, department of obstetrics and gynaecology, University College of medical sciences, Delhi. J Obstet Gynaecol. 2004;54: 365-70.

2. Balakrishnan D, Dibyajyoti G. A comparison between non descent vaginal hysterectomy and total abdominal hysterectomy. J Clin Diagn Res. 2016; 10(1):11-4

3. Kovac SR. Transvaginal Hysterectomy: rationale and surgical approach. Obstet Gynaecol. 2004;103:13215 .

4. Harris WJ. Early Complications of Abdominal and Vaginal hysterectomy. Obstet Gynaecol Surv. 1995; 50:795-805.

5. McCracken G, Lefebvre GG. Vaginal hysterectomy: Dispelling the myths. JOGS. 2007;29(5):424-7.

6. Alokananda R, Luna P, Roshan B, Rashmi C. Non descent vaginal hysterectomy: A constantly improving surgical art. J Obstet Gynaecol. 2011;61: 182-8.
7. Kovac SR. Decision-directed hysterectomy: a possible approach to improve medical and economic outcomes. Int J Gynaecol Obstet. 2000;71:159-69.

8. Bhandra B, Choudhury AP, Nupur AJN. Non descent vaginal hysterectomy: Personal experience in 158 cases. J Med Sci. 2011;4:23-7.

9. Rupali D, Shivani A, Bharti MM, Soumendra KS. Non descent vaginal hysterectomy An experience. J Obstet Gynaencol. 2004;54:376-8.

10. Abrol S, Rashid S, Jabeen F, Kaul S. Comparative analysis of non-descent vaginal hysterectomy versus total abdominal hysterectomy in benign uterine disorders. Int J Reprod Contracept Obstet Gynecol 2017;6:846-9.

11. Saha R, Shrestha NS, Thapa M, Shrestha J, Bajracharya J, Padhye SM. Non-descent Vaginal hysterectomy: Safety and Feasibility. NJOG. 2012; 7(2):14-6.

12. Joshi SA. Comparative study of vaginal hysterectomy and abdominal hysterectomy in nondescent uterus. Indian J Obstet Gynecol Res. 2016;3(4):379-82.

13. Garg P, Malhotra N, Deka D. Vaginal approach for hysterectomy in benign conditions of the uterus at a rural health setting. Obstet Gynaecol Today. 2003; 520-2.

14. Murali MS, Khan A. A comparative study of non-descent vaginal hysterectomy and laparoscopic hysterectomy. J Obstet Gynecol India. 69(4):369-73.

15. Gayathri KB, Sajana G, Manjusha P. Non descent vaginal hysterectomy for benign gynaecological disease: an institutional study on safety and feasibility from South India. IOSR J Dent Med Sci. 2017;16(11):59-63.

16. Deshpande H, Burute S, Malik R. A comparative study of abdominal versus non descent vaginal hysterectomy. Int J Contemp Med Res. 2016;3(4): 1153-6.

17. Chen B, Ren DP, Li JX, Li CD. Comparison of vaginal and abdominal hysterectomy: A prospective non-randomized trial. Pak J Med Sci. 2014;30:875-9.

18. Singh A, Bansal S. Vaginal hysterectomy for non prolapsed uterus. J Obstet Gynaecol India. 2006; 56(2):152-5.

19. Bharatnur S. Comparative study of abdominal versus vaginal hysterectomy in non- descent cases. J Gynecol Obstet. 2010;15:45-9.

Cite this article as: Mujumdar SP, Purohit PK, Navale SS, Upadhyay CM. Comparative study of nondescent vaginal hysterectomy and abdominal hysterectomy at tertiary care centre, Maharashtra. Int J Reprod Contracept Obstet Gynecol 2021;10:3397400. 